\title{
Planejamento urbano em áreas impactadas por Grandes Projetos de Investimentos (GPIS): uma análise sobre o Estado de Rondônia
}

Urban planning in areas impacted by Large Investment Projects (LIPS): an analysis of the State of Rondônia

Rosa Livia Gonçalves Montenegro[a] (D), Luiz Carlos de Santana Ribeiro[b] (D)

[a] Universidade Federal de São João del Rei, São João del Rei, MG, Brasil

[b] Universidade Federal de Sergipe, São Cristóvão, SE, Brasil

Como citar: Montenegro, R. L. G., \& Ribeiro, L. C. S. (2019). Planejamento urbano em áreas impactadas por Grandes Projetos de Investimentos (GPIS): uma análise sobre o Estado de Rondônia. urbe. Revista Brasileira de Gestão Urbana, 11, e20180030. https://doi.org/10.1590/2175-3369.011.e20180030

\section{Resumo}

No Brasil, os grandes projetos de investimentos ligados (GPIs) às obras de infraestrutura são responsáveis por grande geração de emprego e, com efeito, pelo crescimento econômico do país, como é o caso da construção de usinas hidrelétricas no Estado de Rondônia. 0 objetivo deste artigo é discutir os efeitos das implantações e dos projetos de grandes empreendimentos no Estado de Rondônia, para o ano de 2010. Para isso, é utilizada como metodologia a análise fatorial a fim de caracterizar fatores aglomerativos e desaglomerativos das regiões rondonianas. Como insumos da análise fatorial foram utilizadas variáveis proxies para verificar aspectos demográficos, econômicos e de infraestrutura. Os principais resultados apontam para a caracterização de três indicadores distintos e que apresentam características peculiares ao processo de urbanização nos últimos anos em Rondônia. Entre essas características estão cargas fatoriais denominadas de "Dinâmica Econômica", "Infraestrutura básica", pois verificaram-se duas variáveis determinantes de áreas com infraestrutura sólida e/ou não voltadas a áreas urbanas, como água encanada e eletricidade. Quanto ao último fator, ela denomina-se "Natureza Demográfica", pois configura relações típicas de cidade de pequeno porte, porém com relativo déficit na proporção de natalidade e mortalidade, além de outros fatores significativos entre os municípios vizinhos e sua absorção de mão de obra.

Palavras-chave: Planejamento urbano. Grandes Projetos de Investimentos. Rondônia. Análise multivariada. Análise fatorial.

\section{Abstract}

In Brazil, Large Investment Projects (LIPs) linked to infrastructure works are responsible for large job creation and, indeed, for the country's economic growth, such as the construction of hydroelectric plants in the State of Rondônia. The objective of this article is to discuss the effects of the implantations and the projects of large enterprises in the State of Rondônia, for 2010. Thus, the factorial analysis is used as a methodology to characterize agglomeration and deagglomeration factors of the Rondônia regions. As 
inputs to the factorial analysis, proxies were used to verify the demographic, economic and infrastructure aspects. The main results point to the characterization of three distinct indicators that present characteristics peculiar to the urbanization process in recent years in Rondônia. Among these characteristics, there are factorial loads denominated "Economic Dynamics", "Basic Infrastructure", since two variables were determinant of areas with solid infrastructure and/or not directed to urban areas, such as piped water and electricity. As for the last factor, it is called "Demographic Nature", since it configures typical small city relationships, but with a relative deficit in the proportion of birth rate and mortality, besides other significant factors among the neighboring municipalities and their absorption of work.

Keywords: Urban planning. Large Investment Projects. Rondônia. Multivariate analysis. Factor analysis.

\section{Introdução}

Com a recente discussão acerca das obras de implantação da Usina Hidrelétrica de Belo Monte, localizada no Estado do Pará, e seus impactos ambientais e sociais na região em que será construída, vem à tona o tema dos grandes projetos de investimentos (GPIs) na área de infraestrutura e de geração de energia. Nesse contexto, a questão regional também ganha relevância, pois com a implantação de grandes projetos sem estudos prévios para sua viabilidade poderá ocorrer o aprofundamento das desigualdades advindas do processo de acumulação, o que torna necessária a hegemonia do desenvolvimento de toda a infraestrutura básica para auxiliar o crescimento das regiões impactadas.

A literatura econômica é enfática ao argumentar que investimentos em infraestrutura produzem impactos positivos em termos de crescimento do PIB, por exemplo, mas agravam as disparidades regionais (Ribeiro et al., 2018; Domingues et al., 2009; Haddad, 1996; Diniz, 1993).

No caso das construções de grandes usinas hidrelétricas, seus projetos configuram-se como a melhor e a mais viável forma de produzir energia elétrica no território brasileiro. Assim como todo grande empreendimento, a instalação de usinas hidrelétricas de grande porte proporciona efeitos que ultrapassam os limites de sua abrangência, atingindo e alterando estruturas já existentes (Bortoleto, 2001).

Sobre a questão do planejamento regional no país, sua origem foi no Nordeste com a criação da Superintendência de Desenvolvimento do Nordeste (SUDENE), no ano de 1959, e que foi dada continuidade nas demais regiões. Entre as Superintendências criadas estão: Superintendência de Desenvolvimento da Amazônia (SUDAM); Superintendência de Desenvolvimento da Zona Franca de Manaus (SUFRAMA); Superintendência de Desenvolvimento do Centro-Oeste (SUDECO) e Superintendência de Desenvolvimento do Sul (SUDESUL). Com a criação das Superintendências, percebe-se o papel ativo do Estado no planejamento regional e, principalmente, no desempenho dessas instituições que se legitimaram pelo aumento da mão de obra, pela redução de desigualdades regionais, devido em parte aos incentivos fiscais e financeiros proporcionados às atividades que fossem implantadas na região.

Em um planejamento integrado, ao contrário de predominarem as diferenças regionais, é dada ênfase à totalidade nacional. Nesse sentido, o planejamento regional no final da década de 1960 ampliou-se de maneira que buscava atingir todo o país por meio de uma política centralizada, visando a identificação de polos (clusters) para dinamizar economicamente a região por intermédio de programas especiais. Já em meados da década de 1970, as superintendências perderam fôlego e reduziram-se a organismos de acompanhamento local dos projetos nacionais. Nesse mesmo período, entretanto, foram criados programas especiais que possuíam fortes impactos regionais e sociais, os quais foram denominados: Plano de Integração Nacional (PIN) e Programa de Redistribuição de Terras e de Estímulo à Agropecuária do Norte-Nordeste (PROTERRA), fomentados por meio de incentivos fiscais.

$\mathrm{Na}$ ocasião, o planejamento e desenvolvimento regional elaborado pelo Estado visavam preencher a lacuna deixada pelas superintendências e também, com os estímulos de programas especiais, surgiu um novo modelo de planejamento no país que foi denominado Grandes Projetos de Investimentos (GPIs), que será descrito na seção 2. 0 termo "grandes projetos" passou a ser usado com maior frequência a partir da década de 1970, época em que passaram a ser implantados no Brasil projetos de investimento 
que, pelas dimensões técnicas e financeiras, revelaram-se superiores aos empreendimentos até então existentes (Piquet, 1998).

Nos últimos vinte anos, a intervenção do Estado passou a ocorrer por intermédio da implementação de novas políticas setoriais e investimentos em infraestrutura básica para o desenvolvimento brasileiro. No entanto, apesar do enfoque e do conteúdo desenvolvimentista listado pelos planos, eles não alcançavam as necessidades regionais e, em sua totalidade, foram implantados de maneira em que não houve a realização de estudos sobre sua influência regional.

Destarte, houve também forte discurso em nome da industrialização brasileira e da interiorização do desenvolvimento econômico, o qual garantiu que os grandes projetos apresentassem um caráter firme em relação às suas decisões de implantação, incentivos e subsídios estatais. Além disso, a ausência de análises sobre impactos socioeconômicos, culturais e ambientais foram algumas das lacunas encontradas na estrutura dos GPIs.

A grande questão sobre os efeitos desses projetos refere-se às mudanças desses empreendimentos nas regiões, isto é, relacionadas às populações atingidas e ao desenvolvimento econômico local. 0 que se observa em regiões impactadas por esses empreendimentos seria um retrato de desestruturação das atividades preexistentes, como, por exemplo, crescimento populacional desordenado, desemprego, favelização, marginalização social e, geralmente, degradação ambiental (Vainer \& Araujo, 1992).

Busca-se no presente artigo discutir os efeitos das implantações e dos projetos de grandes empreendimentos no Estado de Rondônia, para o período de 2010. Para este estudo é utilizada como metodologia a análise fatorial, a fim de caracterizar fatores aglomerativos e desaglomerativos das regiões rondonianas. Como insumos da análise fatorial foram desenvolvidas variáveis proxies para verificar aspectos demográficos, econômicos e de infraestrura.

Portanto, o objetivo geral do trabalho é analisar o estado de Rondônia pela ótica da implantação de grandes projetos na infraestrutura. 0 referido estado foi escolhido em virtude de sua magnitude no recebimento de investimentos em obras realizadas pelo Programa de Aceleração do Crescimento (Brasil, 2008), que obteve um montante total de investimentos (antes e após 2010) de $R \$ 28,1$ bilhões, em obras destinadas às áreas logística, energética, social e urbana. Adicionalmente, a principal contribuição do trabalho é avaliar a influência das variáveis determinantes de infraestrutura. A suposição de que variáveis que compõem os aspectos demográficos, econômicos e de infraestrutura, com naturezas distintas, possam evidenciar as diferenças identificando os vários conjuntos de fatores das variáveis analisadas é o foco da análise do artigo.

A partir da análise fatorial será possível caracterizar e descrever a variabilidade das variáveis e, assim, observar as proximidades entre indivíduos e os vínculos entre os fatores. Desse modo, o artigo é dividido em sete seções. Após a introdução são abordados aspectos teóricos do planejamento urbano. Na terceira seção é descrito um breve contexto histórico e realizada uma análise preliminar da infraestrutura do Estado de Rondônia e são discutidas as principais considerações sobre os GPI's no Estado de Rondônia: a implantação da UHE Santo Antônio, UHE Jirau e a UHE Samuel. A quarta e a quinta seções são reservadas para a proposta metodológica e as descrições dos resultados, respectivamente. Por fim, na última seção, são tecidas as conclusões do trabalho.

\section{Alguns aspectos teóricos do planejamento urbano}

É amplamente discutido na literatura que o planejamento urbano é formado por aspectos históricos, particularmente, desde as reestruturações e reorganizações do espaço socioeconômico nas origens do capitalismo urbano industrial. Essa abordagem também é equivalente para as novas formações do espaço urbano no mundo contemporâneo (Soja, 2000). Não obstante, a história da industrialização brasileira revela-se como um dos fatores mais marcantes na transformação das cidades em metrópoles e na configuração da rede urbana no território, isto é, a reestruturação produtiva (Magalhães, 2008). 
Para maior aprofundamento da temática sobre planejamento territorial, Moura (2011) afirma que, no caso de políticas territoriais, a intervenção nas cidades ocorre por meio de Grandes Projetos Urbanos (GPUs). Os GPUs, segundo a autora, representam o espaço globalizado, reunindo o público e o privado, e incita as diversas formas de ação do Estado sobre o território. Em resumo, há uma sinergia de forças territoriais que potencializam os investimentos na reabilitação de bairros, revitaliza e dispersa as atividades terciárias como escritório de grandes corporações, hotéis, bancos e restaurantes, por exemplo.

Os GPUs se formam a partir de programas de intervenção sob um conjunto de ações urbanas em nível intermediário, no qual sua integração tem um profundo impacto no desenvolvimento de uma cidade. A importância do estudo dos GPUs decorre da profunda transformação do movimento de globalização, a qual redefine as funções das cidades e coloca a questão da competitividade em primeiro lugar, de acordo com o processo de planejamento de desenvolvimento das cidades (Lungo, 2005). A ideia que está por trás dos GPUs vem acompanhada pelo processo de associação com as parcerias público-privada, como o fator-chave do desenvolvimento das cidades.

Sob esse enfoque, Ultramari (2006a) descreve algumas considerações sobre os GPUs para o Brasil e destaca a valorização do interesse privado sobre o interesse coletivo, como no caso das parcerias públicoprivadas. No caso brasileiro, a fragilidade das administrações públicas não consegue impor um projeto mais transformador para as cidades, aliado a uma estratégia avançada e integrada a diversos setores da economia (Ultramari, 2006b). O espaço urbano, nesse caso, é fruto de uma estrutura construída "em pedaços", com características de periferização e áreas tradicionais da cidade subutilizadas.

De acordo com Harvey (1975), em uma visão mais sistêmica, o planejamento urbano representa um estágio da história e deve ser tratado como um conjunto de relações sociais no qual reflete as ligações estabelecidas em uma sociedade como um todo. Nesse sentido, as áreas urbanas, suburbanas e rurais são afetadas e incluídas dentro do processo de urbanização. Monte-Mór (2006) ressalta que as áreas rurais vêm se urbanizando ao longo do tempo, à medida que as condições de produção urbano-industriais, antes restritas às cidades, se estenderam para além dos limites legais do espaço urbano e adquiriram dimensão regional e, até mesmo, nacional.

Segundo Lefebvre (1999), a sociedade urbano-industrial alinha-se a uma expressão do espaço social (re)definido pela urbanização e estendido por todo o território a partir da rede urbana. Essa concepção também leva a afirmar que as grandes cidades industriais se estendem sobre suas periferias de modo a "acomodar" a necessidade de produção e a lógica das suas indústrias, seus fornecedores e trabalhadores, gerando amplas regiões urbanizadas no seu entorno: as regiões metropolitanas (Monte-Mór, 2006).

Além disso, essa relação da sociedade industrial com a sociedade urbana implica mudanças adicionais nas quais estão inseridas colocações de conflitos sociais, como, por exemplo, força de trabalho e excedente econômico na qual as relações sociais ocorrem dentro de um determinado modo de produção. Soja (2000) afirma que no mundo contemporâneo o espaço urbano-regional guarda as especificidades locais, embora o processo de globalização e seus padrões homogêneos tenham invadido as localidades. Existem, então, transformações e crescimento constante do espaço urbano que culmina na formação da própria rede urbana, diferentes graus de identidades locais com padrões de globalização (por exemplo, culturas, estrutura de pensamento, regime de produção e de regulação social e política).

Ademais, o espaço urbano regional, com base na cultura, sociedade e economia, abrange e expande para todas as demais regiões urbanizadas no mundo. Ao contrário, um centro urbano individual, seja ele grande ou pequeno, contém um "mundo" inteiro dentro de si.

Em relação ao Brasil, o planejamento urbano, particularmente, possui características voltadas à centralidade urbana e um processo econômico fortemente controlado por políticas governamentais. Vainer (2007) explica que, entre as décadas de 1950 e 1970, surgiu a necessidade de desenvolver os sistemas urbanos em função dos grandes projetos de investimentos. Os GPI's, segundo o autor, traduzem uma forma de organização territorial e que, intrinsecamente, fragmentam o território e instauram enclaves regionais. Nesse ponto, o planejamento governamental proposto volta-se para outro problema, o aprofundamento das contradições sociais, devido a alguns elementos do processo de fragmentação do 
território, pode-se citar: êxodo rural, urbanização expressiva e a industrialização glocalizada (espaços globais locais estratégicos).

Sobre esse assunto, Monte-Mór (2004) e Bernardes (1986) afirmam que o aprofundamento do processo de urbanização brasileiro se consolidou em meados da década de 1960, em que o uso do território passou a desempenhar papel importante na formulação de políticas públicas, voltadas diretamente ao planejamento regional urbano.

No caso das políticas urbanas específicas, há um consenso entre os autores Vainer (2007), Monte-Mór (2004) e Bernardes (1986), de que o desenvolvimento urbano brasileiro é fruto de políticas setoriais e de infraestrutura voltadas à criação de condições favoráveis à questão urbana. Entretanto, as transformações econômicas, políticas, sociais e culturais que sucederam posteriormente a essas políticas levam ao questionamento das fragmentações e lacunas observadas territorialmente.

Isto equivale a dizer que, apesar do esforço das políticas governamentais em fomentar um planejamento urbano capaz de articular diferentes esferas no campo sociespacial e econômico, não se observou o avanço desejado, e alguns problemas surgiram e/ou se agravaram.

Entre os problemas que se pode destacar estão o crescimento desordenado da população urbana brasileira, problemas de desenvolvimento industrial, de integração espacial, territorial e desequilíbrios regionais (Monte-Mór, 2004). Vale ressaltar que esses aspectos não se configuram especificamente às políticas governamentais implementadas, porém, referem-se ao (in)consequente crescimento das cidades, às aglomerações urbanas e às articulações setoriais e empresariais.

Tendo uma visão generalizada do planejamento urbano brasileiro, observa-se que em todos os aspectos houve ganho de infraestrutura significativo. A expansão da urbanização proporcionou ganho de espaço regional às pequenas localidades que antes não possuíam ou tinham limitações ao acesso de serviços urbanos básicos (água encanada, saneamento, eletrificação), comunicação, pavimentação de estradas e rodovias, como foi o caso das estratégias, grandes projetos de investimento e planos de desenvolvimento regional, o que também podem ser chamados de fatores aglomerativos.

No caso dos GPIs, os planejadores públicos visavam o (re)desenho da região, proporcionando fomento nos grandes setores (elétrico, minero-metalúrgico e petroquímico) (Vainer, 2007). Em relação ao plano desenvolvimentista ligado às áreas de infraestrutura e de energia, como o Plano de Metas do governo Kubistchek, sua repercussão foi extremamente importante ao debate das transformações urbanas que vieram posteriormente, garantindo maior bem-estar social.

Destarte, apesar do desenvolvimento urbano observado, houve uma fragmentação provocada pelo modo particular de cada campo de atuação das políticas implementadas, ocasionando, de modo geral, os desequilíbrios regionais. Ao mesmo tempo em que as políticas se tornaram motores propulsores do crescimento e da urbanização das cidades, elas se tornaram um "divisor de águas", isto é, criaram alguns enclaves territoriais (econômicos, políticos, sociais, culturais e ambientais), contribuindo, ao mesmo tempo, para um espaço nacional integrado e fortemente desigual (Vainer, 2007; Monte-Mór, 2004). Na verdade, os padrões de urbanização reforçaram a concentração urbana, principalmente na região Sudeste, e promoveram a desconcentração nas regiões detentoras de pequenas e médias cidades.

A partir das experiências urbanas observadas, podem-se sugerir algumas estratégias de forma a delinear um panorama dinâmico de planejamento urbano-regional brasileiro. Para tanto, os aspectos em relação à escala local (intraurbana) devem ser levados em consideração. Isto é, deve haver maior coordenação e gestão das ações em função da caracterização e diferenciação das "categorias espaciais" (Bernardes, 1986).

\section{Breve contexto histórico, análise preliminar da urbanização do Estado de Rondônia e o Complexo do Madeira}

A história de Rondônia inicia-se no período entre 1541 e 1542, quando o explorador espanhol Nuflo de Chaves teria chegado até o vale do Rio Guaporé. Em seguida, com o início da exploração portuguesa, 
1648 a 1651, outros rios da região Norte foram sendo descobertos, como os rios Mamoré, Madeira e Amazonas. Já no século seguinte, os bandeirantes intensificaram a exploração da região do Vale do Guaporé motivados pela descoberta de ouro no vale do rio Cuiabá, em Goiás e Mato Grosso (Rondônia, 2009). Mais tarde, apesar da grande corrida ao ouro nessa região, ocorre perda de dinamismo econômico em razão, principalmente, da independência do Brasil.

Em meados do século XIX, Brasil e Bolívia firmaram um acordo para aquisição do Acre, e também formaram um consórcio de empresas anglo-americanas para a construção da estrada de ferro MadeiraMamoré, sendo regularizada com a assinatura do Tratado de Petrópolis, em 1903, período em que surgiram os primeiros povoados na região (Rondônia, 2009).

Legitimamente, o território de Rondônia foi criado pelo Decreto-Lei n. 5.812, de 13 de setembro de 1943, a partir das áreas desmembradas dos Estados de Amazonas e Mato Grosso. Nesse período, houve forte migração de populações oriundas dos Estados do Amazonas e do Ceará, o que contribuiu para que a população aumentasse em mais de 85\% entre os anos de 1950 e 1960. Devido à queda do preço da borracha (principal produto fabricado no Estado) e a constante migração, grande parte da população passou a se dedicar mais ao setor agrícola. Ademais, logo após a descoberta da cassiterita, houve intenso processo de mineração no território federal de Guaporé. A mudança do nome de território de Guaporé para território de Rondônia foi uma homenagem ao desbravador Marechal Cândido Mariano da Silva Rondon, sendo realizado no dia 17 de fevereiro de 1956. Somente em 1981 o território federal de Rondônia passou a ser um dos Estados da Federação do Brasil (Rondônia, 2009).

Atualmente, o Estado de Rondônia possui 52 municípios e tem predominância em atividades na agricultura e no extrativismo (IBGE, 2009). A economia rondoniana baseia-se, principalmente, na produção de mandioca, milho, arroz, café e no extrativismo, em que a cassiterita é o principal produto de exploração mineral. 0 município de Porto Velho (1), indicado na Figura 1, é a capital de Rondônia e o maior entre todos os seus municípios, tanto em extensão territorial quanto em população. De acordo com o Censo 2010, há 356.376 habitantes somente no município, que se localiza na margem direita do Rio Madeira.

Ao todo, o Estado possui 1.294.647 habitantes, segundo o Censo de 2010, sendo que $28 \%$ vivem na capital. Entre todos os 52 municípios do Estado apenas oito deles possuem taxa de urbanização de 2,8\% a 3,5\%, conforme podem ser visualizados na Figura 1, são eles: Porto Velho (1); Guajará-Mirim (2); Ji-Paraná (3); Ariquemes (4); Cacoal (5); Pimenta Bueno (6); Vilhena (7); Cerejeiras (8).

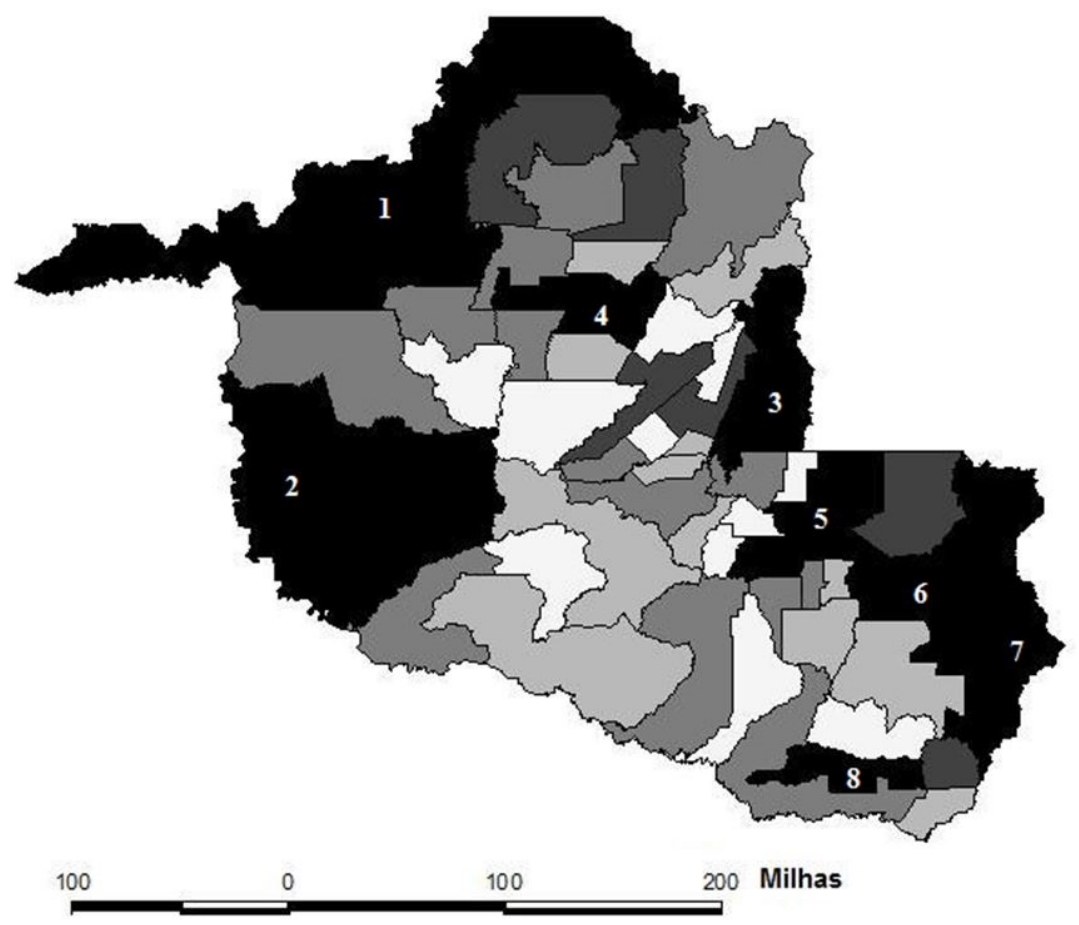

Legenda

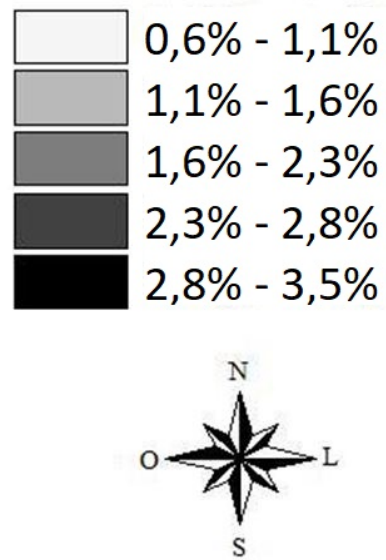

Figura 1 - Taxa de urbanização dos municípios de Rondônia (2009). Fonte: Elaboração própria (IBGE, 2010). 
0 adensamento urbano observado na cidade de Porto Velho em 2010 é, em grande medida, fruto das obras de implantação das Usinas Hidrelétricas do Complexo Madeira, o que será detalhado na próxima seção. Geralmente, as obras de grandes projetos de investimento tendem a atrair mão de obra de diferentes lugares, de forma direta e indireta, de modo que se a capacidade de absorção do município for menor que o crescimento populacional, esse resultado poderá ocasionar efeitos indesejáveis, tanto para a população residente quanto para a administração municipal e para o próprio empreendedor (AHE Santo Antônio, 2008).

Além disso, a carência de investimentos no Estado é elevada. Segundo dados do Conselho Federal de Medicina (CFM), para cada 10 mil habitantes existem sete médicos, o que significa a metade do considerado aceitável pela Organização Mundial de Saúde (OMS) (Rondônia, 2009). Em relação ao nível educacional da população, de acordo com os dados do Censo 2010,12\% dos habitantes maiores de 15 anos são analfabetos, o que representa um valor bem elevado, em comparação à média nacional, que é de $9,7 \%$.

As recentes iniciativas governamentais e privadas para favorecer o país com uma infraestrutura de serviços, abrangendo eletrificação, estradas, portos, aeroportos e comunicações, são importantes e indispensáveis para a concretização dos mais diferentes projetos econômicos, sociais, culturais, e propicia o bem-estar das populações das áreas urbanas e rurais (Santos, 2007).

No caso do Estado de Rondônia, o Rio Madeira, que também é afluente do Rio Amazonas e considerado o principal rio da região, corta o Estado e é considerado como o fator-chave no aspecto socioeconômico devido aos impactos ocasionados pela construção das hidrelétricas. Outro rio importante na região é o Rio Jamari, que é afluente do Rio Madeira e que deu origem à construção da primeira usina hidrelétrica na região, a Usina Hidrelétrica (UHE) de Samuel.

A UHE de Samuel começou a ser construída no ano de 1982 com prazo de início da geração de energia para quatro anos depois. Entretanto, devido à falta de verbas e investimentos, a UHE de Samuel foi inaugurada quatorze anos depois. Em 2009, a UHE alcançou recorde histórico de geração de energia, o equivalente a 910.889 megawatts-hora (MWh) no total do ano ${ }^{1}$. A UHE de Samuel possui uma potência instalada de 216 MW e foi concebida inicialmente para suprir as cidades rondonienses de Guajará-Mirim, Ariquemes, Ji-Paraná, Pimenta Bueno, Vilhena, Abunã e Porto Velho. Em 2002, a cidade de Rio Branco (capital do Acre) passou a ser abastecida também com a energia da UHE Samuel (Eletronorte, 2018).

Em 2007, com o avanço de processos político-administrativos na região, foram disponibilizados pelo governo federal recursos para a construção das UHE de Jirau e Santo Antônio. Nesse sentido, o Complexo do Madeira, em Rondônia, foi constituído e se tornou alvo de polêmicas, debates entre os países (Bolívia e Brasil) e discussões regionais e locais (Verdum, 2007). 0 principal objetivo do Complexo é gerar $6.450 \mathrm{MWh}$ de energia, equivalente a $8 \%$ de toda a energia produzida pelo país. Ambas UHEs do Complexo estão localizadas na cidade de Porto Velho, considerada uma região onde concentra 50\% de todo potencial hidrelétrico do Brasil. Deve-se ressaltar que, sendo obra de grande porte e estratégica, poderá acarretar efeitos profundos sobre as áreas ambientais, econômicas, sociais e institucionais.

De acordo com o Estudo de Impacto Ambiental (EIA), o efeito no centro urbano de Porto Velho será intenso, visto que a UHE Santo Antônio está localizada a $7 \mathrm{~km}$ do centro. Deste modo, alguns aspectos na cidade de Porto Velho e nas cidades vizinhas a ela devem ser analisados e monitorados, procurando diminuir os efeitos negativos dos impactos de implantação das obras na qualidade de vida da população. Dentre esses fatores estão: (a) adensamento populacional; (b) equipamentos urbanos e comunitários (em hospitais, lugares públicos etc.); (c) uso e ocupação do solo; (d) especulação imobiliária; (e) geração de tráfego e demanda por transporte público; (f) aumento da criminalidade; (g) paisagem urbana e patrimônio natural e cultural (Moret \& Guerra, 2009).

Além da previsão das UHEs, há também a criação de Complexo Hidroenergético e Viário do Rio Madeira, sendo responsável pelas obras a Construtora Norberto Odebrecht em parceria com a estatal Furnas Centrais Elétricas S.A., com um investimento inicial que varia de $R \$ 18,4$ bilhões a $R \$ 28$ bilhões, sendo um dos principais e mais importantes projetos do PAC.

\footnotetext{
${ }^{1}$ Esse recorde ainda é pequeno quando comparado aos valores da Usina Hidrelétrica de Itaipu, cujo recorde de geração de energia em 2016 foi de 51.637.234 MWh (Itaipu, 2016).
} 
O projeto do Complexo Hidroviário também faz parte da Iniciativa de Integração da Infraestrutura Sul-Americana (IIRSA), dentro da qual é uma iniciativa formada por 12 países $^{2}$ da América do Sul e teve início em setembro de 2000 com o objetivo de desenvolver a infraestrutura de transporte, energia e telecomunicações no aspecto regional. O IIRSA também conta com o apoio do Banco Interamericano de Desenvolvimento (BID) e do Banco Nacional de Desenvolvimento Econômico e Social (BNDES), que permitem a realização das obras de grande porte por meio de empréstimos (Brasil, 2011).

Entretanto, em Rondônia é possível observar os reais interesses e os impactos envolvidos no Complexo Hidrelétrico e Viário do Rio Madeira e os duvidosos e indefinidos resultados positivos anunciados pelo governo e pelos interesses empresariais e financeiros (Verdum, 2007).

Além disso, Moret \& Guerra (2009) ressaltam que as situações político-institucional e econômica que o Estado de Rondônia e principalmente a cidade de Porto Velho vivem em relação ao licenciamento dos empreendimentos foram influenciadores das forças políticas, de tal forma que possibilitaram a aprovação da construção das UHEs. Isto é, a imprensa local e marketings institucionais faziam propaganda da futura geração de empregos e do aumento da atividade econômica sustentada local (Moret \& Guerra, 2009).

0 mais importante em todo e qualquer grande projeto de investimento, que oferece riscos e significativos impactos regionais, seria o esgotamento da discussão entre a sociedade e o empreendedor. É necessário que haja a elaboração de Estudos de Impactos Ambientais (EIA) mais eficazes e precisos na avaliação e implantação dos grandes projetos, inclusive com sua ampla divulgação aos atores locais, regionais e nacionais.

Após a discussão teórica sobre o planejamento urbano e a apresentação das características urbanas e históricas de Rondônia, é descrita a seguir a análise fatorial que visa contribuir para a melhor observação das variáveis ligadas à infraestrutura, economia e áreas sociais dos municípios de Rondônia.

\section{Análise fatorial e base de dados}

A análise fatorial (AF) possibilita reduzir a quantidade de variáveis por índices resultantes combinações lineares das variáveis econômicas selecionadas. Os seus principais objetivos referem-se à redução de dimensionalidade dos dados (espaço das variáveis); obtenção de combinações interpretáveis das variáveis originais; descrição e entendimento da estrutura de correlação das variáveis. Grosso modo, a Equação 1 especifica esta técnica multivariada.

$X_{i}=a_{i j} f_{i}+\varepsilon_{i}$

em que o vetor $X_{i}=\left(X_{1}, X_{2}, \ldots, X_{p}\right)^{t}$ é formado pelas variáveis aleatórias observáveis; $f_{i}=\left(f_{1}, f_{2}, \ldots, f_{r}\right)^{t}$ é um vetor que representa os fatores; $a_{i j}$ é uma matriz com as cargas fatoriais; e $\varepsilon_{i}=\left(\varepsilon_{1}, \varepsilon_{2}, \ldots, \varepsilon_{p}\right)^{t}$ é um vetor de erros aleatórios.

A AF simplifica uma grande quantidade de variáveis em um número menor de fatores independentes, de tal forma que estes possam explicar boa parte da variância total da amostra sem perda significativa de informação (Manly, 1986; Mingoti, 2007; Cardoso \& Ribeiro, 2015). Em outras palavras, segundo Mingoti (2007), a AF descreve a variabilidade original do vetor $X_{i}$ a partir de uma quantidade menor de fatores. Para a extração dos fatores, utilizou o método dos componentes principais, recomendado por Hoffman (1993) por ser o mais utilizado na literatura.

Todas as variáveis foram padronizadas para evitar problemas de escalas. Usualmente, os fatores extraídos não possibilitam fácil interpretação. Nesse sentido, a rotação possibilita a transformação dos coeficientes dos fatores retidos em uma estrutura simplificada. Neste artigo, utilizou-se o método

\footnotetext{
2 Os doze países envolvidos na IIRSA são: Argentina, Brasil, Uruguai, Chile, Bolívia, Paraguai, Peru, Equador, Colômbia, Venezuela, Guiana
} e Suriname. 
Varimax de rotação ortogonal, que minimiza o número de variáveis com maior peso relacionas a cada fator (Fávero et al., 2009).

Em termos práticos, segundo Fávero et al. (2009), a AF pode ser operacionalizada a partir das seguintes etapas: i) análise da matriz de correlações e adequação da utilização da AF; ii) extração de fatores iniciais (ACP) e determinação do número de fatores; iii) rotação dos fatores; e iv) interpretação dos fatores.

A base de dados para o estudo para os 52 municípios de Rondônia corresponde aos indicadores sociais do Censo 2010, divulgados pelo Instituto Brasileiro de Geografia e Estatística (IBGE). Os indicadores econômicos, tais como número de unidades locais, pessoal ocupado total e empresas atuantes referem-se à base que também foi disponibilizada pelo IBGE, para o ano de 2009, sendo as informações mais atualizadas destes indicadores.

As variáveis consideradas na análise são indicadores que permitem identificar fatores aglomerativos e desaglomerativos urbanos, descritos na primeira seção do trabalho. Para a análise fatorial são utilizadas variáveis proxies para verificar aspectos demográficos, econômicos e infraestrurais, que são descritas e divididas em três dimensões, a saber:

1. Aspectos demográficos:

a. Popurb: proporção de pessoas residentes em áreas urbanas;

b. Varpop: taxa de crescimento da população total residente entre 2001 e 2010;

c. Mort: proporção do número de óbitos ocorridos na localidade.

2. Aspectos econômicos:

d. Empra: proporção do número de empresas atuantes na localidade;

e. Pot: proporção de pessoas ocupadas no município.

3. Aspectos de infraestrutura:

f. Água: proporção de domicílios particulares permanentes com acesso a água canalizada;

g. Eletric: proporção de domicílios particulares permanentes com energia elétrica de companhia distribuidora;

h. Sane: proporção de domicílios particulares permanentes por tipo de saneamento adequado; e

i. Const: \% do setor de Construção civil no emprego total do município.

Pretende-se, com a utilização das variáveis descritas acima, à luz da economia regional, caracterizar e especificar os determinantes das regiões de maior e menor densidade urbana. A aplicação da análise fatorial sobre o conjunto de indicadores possibilitará extrair de forma condensada e reduzida as características dos indicadores dos municípios de Rondônia. Na verdade, o objetivo da tipologia proposta é gerar uma base de componentes relativamente homogêneos quanto a um conjunto de variáveis que poderiam caracterizar economias locais. É importante ressaltar que a análise fatorial fornece um número de fatores igual ao número de variáveis originais, todavia é interessante considerar um número mínimo de fatores que contenham a maior parte da variabilidade do vetor aleatório.

\section{Discussão de resultados}

Após a descrição das variáveis, é analisada nesta seção a utilização da análise fatorial para os 52 municípios rondonianos, considerando 9 variáveis originais (vetor aleatório), nos anos de 2009 e 2010. No entanto, antes disso, foi realizada uma primeira análise descritiva dos dados com as médias, desvios padrões e valores mínimos e máximos de cada uma das variáveis. 
Tabela 1 - Análise descritiva das variáveis

\begin{tabular}{cccccc}
\hline Blocos & Variáveis & Média & Desvio padrão & Mínimo & Máximo \\
\hline Aspectos demográficos & Popurb & 0,51 & 0,22 & 0,16 & 0,94 \\
& Varpop & 1,17 & 0,22 & 0,52 & 1,57 \\
\multirow{3}{*}{ Aspectos econômicos } & Mort & 0,005 & 0,002 & 0,0008 & 0,009 \\
& Empra & 0,12 & 0,01 & 0 & 0,04 \\
Aspectos de infraestrutura & Pot & 0,13 & 0,07 & 0,06 & 0,46 \\
& Agua & 0,36 & 0,01 & 0,32 & 0,37 \\
& Eletric & 0,34 & 0,02 & 0,29 & 0,37 \\
& Sane & 0,05 & 0,09 & 0 & 0,5 \\
& Const & 0,02 & 0,03 & 0 & 0,21 \\
\hline
\end{tabular}

Fonte: Elaboração própria com base nos indicadores do IBGE $(2009,2010)$.

Na Tabela 1 observa-se que as variáveis pertencentes ao bloco de aspectos demográficos informam que a densidade demográfica é muito diferente nos vários municípios, encontrando-se regiões com elevada densidade demográfica, típicas de metrópoles, e outros com população com menor densidade. Já o bloco de aspectos econômicos apresenta variáveis com valores semelhantes, com exceção da variável relacionada ao mercado de trabalho (Pot), que indica maior dispersão de trabalhadores ocupados nos municípios. E, por fim, os aspectos de infraestrutura revelam que há grande heterogeneidade entre os municípios no que diz respeito a saneamento e construção civil, o que justifica a busca para a análise regional que leve em conta tal diversidade.

Após a análise descritiva das variáveis, foi utilizada a análise fatorial aplicada aos 52 municípios rondonianos, considerando as 9 variáveis originais (vetor aleatório). Antes da análise dos resultados pelo método fatorial, é necessário avaliar se as variáveis mensuradas estão em conformidade com os principais testes fatoriais. Pela Tabela 2 pode-se observar os testes de adequação à análise fatorial de acordo com a medida de adequação de Kaiser-Meyer-Olkin (KMO).

Tabela 2 - Testes de adequação à análise fatorial

\begin{tabular}{ccc}
\hline \multicolumn{2}{c}{ Medida de adequação de Kaiser-Meyer-Olkin (KMO) } & $\mathbf{0 , 7 0}$ \\
\hline \multirow{3}{*}{ Teste de Esfericidade de Bartlett } & Estatística & 178,30 \\
& Graus de liberdade & 36 \\
& Probabilidade & 0 \\
\hline
\end{tabular}

Fonte: Elaboração própria.

Pelo valor do teste $(0,70)$ é possível afirmar a adequacidade do ajuste do modelo de análise fatorial, pois quanto mais próximo de 1 melhora adequação dos dados. Contudo, Mingoti (2007) afirma que se deve ter cautela ao utilizar apenas o valor de KMO como ponto de partida para ajustar ou não um modelo de análise fatorial ortogonal aos dados.

Desta forma, foi realizado conjuntamente o teste de esfericidade de Bartlett. 0 ajuste de um modelo de análise fatorial aos dados supõe que as variáveis utilizadas sejam correlacionadas entre si. Assim, é possível fazer o teste de hipótese para verificar se a matriz de correlação populacional é próxima ou não da matriz identidade. Para que o modelo de análise fatorial possa ser ajustado, o teste de Barlett deve rejeitar a hipótese nula (Mingoti, 2007). Logo, observa-se na Tabela 2 o resultado do teste de esfericidade de Barlett, que indicou um valor $\mathrm{T}$ igual 178,30, com a probabilidade igual a zero e a hipótese nula rejeitada, indicando que o modelo de análise fatorial está ajustado. Além disso, o teste de Bartlett rejeita a hipótese nula de que a matriz de correlação entre as variáveis seja uma matriz identidade.

De acordo com a Tabela 3, observam-se os resultados dos três fatores com os seus respectivos autovalores e o percentual da variância explicada e da variância acumulada. A partir do uso do método de rotação ortogonal Varimax, foi possível extrair três fatores que possuem autovalores superiores à unidade. Eles explicam aproximadamente $70 \%$ da variabilidade total dos 9 indicadores selecionados (Tabela 3). Em outras palavras, isto significa que a perda de informação é de apenas $30 \%$, ao mesmo tempo em que o banco de dados é reduzido, pois em vez de 9 indicadores, pode-se agora trabalhar com apenas 3 . 
Tabela 3 - Raízes características e variância dos fatores

\begin{tabular}{cccc}
\hline Fatores & Raiz característica & \% da variância dos fatores retidos & \% da variância acumulada \\
\hline 1 & 3,46 & 38,4 & 38,4 \\
2 & 1,62 & 18,0 & 56,4 \\
3 & 1,16 & 12,9 & 69,3 \\
\hline
\end{tabular}

Fonte: Elaboração própria.

A Tabela 4 mostra as cargas fatoriais e as comunalidades que descrevem a quantidade de variância levada em consideração por cada variável (Gonçalves, 2006). Quando as comunalidades são elevadas, como na maioria das variáveis apresentadas, elas indicam que os componentes extraídos representam bem a variável.

A pior representação ocorre para a variável "Proporção do número de empresas atuantes na localidade". Em seguida, tem-se a variável "Proporção de domicílios particulares permanentes por tipo de saneamento adequado" com comunalidade de 0,55. Neste caso, contudo, mais da metade de sua variância pode ser reproduzida pelos fatores comuns. Quanto às cargas fatoriais, o valor de cada coeficiente da Tabela 4 exprime a relação que existe entre cada uma das variáveis e os respectivos fatores. É oportuno ressaltar que a rotação desses fatores obteve êxito, pois cada variável apresenta forte relação com apenas um fator, o que implica uma interpretação mais fácil. Para auxiliar na análise dos resultados, apenas os coeficientes com valor acima de 0,5 são exibidos.

Tabela 4 - Matriz de componentes e comunalidades dos indicadores após rotação Varimax

\begin{tabular}{ccccc}
\hline \multirow{2}{*}{ Variáveis } & \multicolumn{2}{c}{ Fatores } & Comunalidades \\
\cline { 2 - 4 } & $\mathbf{1}$ & $\mathbf{2}$ & $\mathbf{3}$ & 0,830 \\
\hline pot & 0,901 & - & - & 0,549 \\
empra & 0,665 & - & - & 0,550 \\
sane & 0,739 & - & - & 0,745 \\
eletric & - & 0,822 & - & 0,832 \\
agua & - & 0,899 & - & 0,778 \\
popurb & 0,835 & - & - & 0,780 \\
varpop & - & - & $-0,881$ & 0,599 \\
mort & - & - & 0,676 & 0,578 \\
const & 0,735 & - & - & - \\
\hline
\end{tabular}

Fonte: Elaboração própria.

O primeiro fator, que leva em consideração 38,4\% da variância de todas as variáveis (Tabela 3), é mais altamente correlacionado com as variáveis vinculadas aos aspectos econômicos (Tabela 4). Assim, pode-se chamar este primeiro fator de "Dinâmica econômica". 0 segundo fator, que explica $18 \%$ da variabilidade total dos dados (Tabela 3), apresenta coeficientes positivos e de alta magnitude. Este segundo fator é denominado de "Estrutura básica", pois as duas variáveis (proporção de domicílios particulares permanentes com acesso a água canalizada e proporção de domićlios particulares permanentes com energia elétrica de companhia distribuidora) são características dos aspectos de infraestrutura. Por último, o terceiro fator, que representa aproximadamente $13 \%$ da variância total, pode ser chamado de "Natureza demográfica", pois ambas variáveis (variação relativa da população total residente entre 2001 e 2010 e a proporção do número de óbitos ocorridos na localidade) configuram aspectos demográficos. Vale destacar que a variável (varpop) indicou sinal negativo, o que poderia denotar uma mobilidade dos indivíduos entre municípios vizinhos ou um êxodo populacional para municípios ou regiões com maiores e melhores condições de vida e de trabalho. 
As Figuras 2, 3 e $4^{3}$ objetivam espacializar os três fatores criados, no sentido de identificar padrões espaciais entre os municípios rondonienses. Ainda de acordo com os resultados das Figuras, é oportuno ressaltar a localização das três hidrelétricas mais importantes destacadas no trabalho, a saber, a UHE Santo Antônio e a UHE Jirau, que se localizam em Porto Velho (17), e a UHE Samuel localizada em Candeias do Jamari (32).

A Figura 2 mostra a "Dinâmica econômica" de Rondônia com base na ótica das variáveis selecionadas nas cargas fatoriais. Por intermédio da Figura 2, observa-se que há uma heterogeneidade entre os municípios com maiores proporções da carga fatorial "Dinâmica econômica", como é o caso de: Ji-Paraná, Cacoal, Pimenta Bueno, Porto Velho e Vilhena. Estes municípios supracitados estão próximos aos municípios de baixa e média proporções desta carga fatorial, como, por exemplo: Cabixi, Campo Novo de Rondônia, Seringueiras, Teixeirópolis, Corumbiara, Parecis, Itapuã do Oeste, Buritis, São Felipe D'Oeste, Ariquemes. A "Dinâmica econômica" se explica pela elevada taxa de urbanização e por grande parte das obras da hidrelétrica se concentrarem na capital Porto Velho. Os efeitos de externalidades ainda se encontram contidos em algumas localidades, porém se observa algum espraiamento entre as regiões de baixa e média proporções.

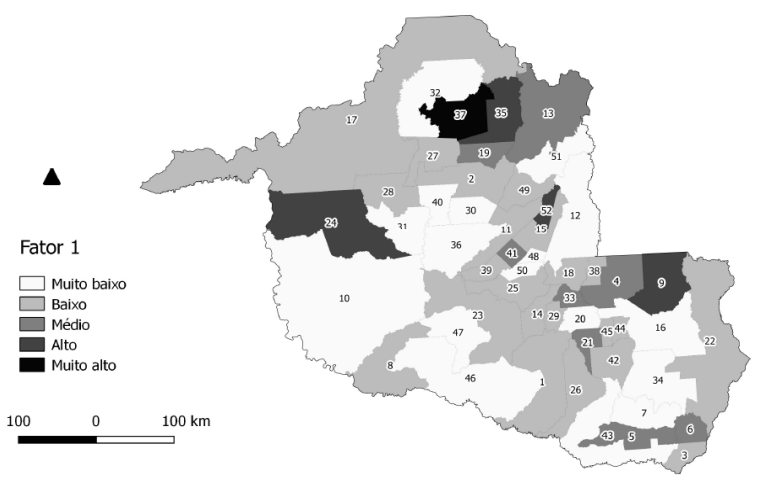

Figura 2 - Dinâmica econômica. Fonte: Elaboração própria.

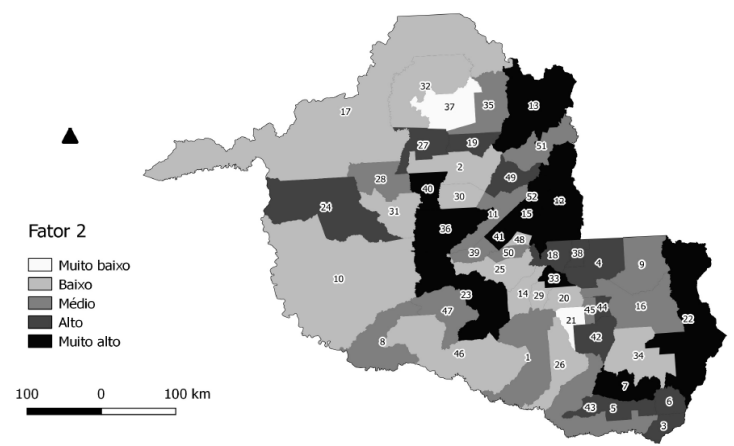

Figura 3 - Estrutura básica. Fonte: Elaboração própria.

Com relação à "Estrutura básica" (Figura 3), em que o perfil da carga fatorial concentrou-se nas proporções de domićlios particulares permanentes com acesso a água canalizada e proporção de domicílios particulares permanentes com energia elétrica de companhia distribuidora, o seu resultado foi bastante satisfatório. Apenas dois municípios apresentaram proporções muito baixas da condição de "Estrutura básica", são eles: Guajará-Mirim e Porto Velho. A surpresa desse resultado, apesar de ambos municípios terem apresentado uma elevada "Dinâmica eonômica", converge com as disparidades presentes em ambas localidades com grandes dimensões e peculiaridades. A capital de Rondônia, Porto Velho, concentra grande parte das atividades econômicas do Estado e abrange duas grandes obras de Usina Hidrelétrica (UHE Santo Antônio e UHE Jirau). Contudo, o município ainda não é capaz de atender ao seu território aspectos básicos de infraestrutura como água canalizada e energia elétrica. A taxa de

${ }^{3} 0$ Anexo 1 mostra a legenda com o nome dos 52 municípios. 
mortalidade infantil média na cidade é de 13,36 para 1.000 nascidos vivos. As internações devido a diarreias são de 0,6 para cada 1.000 habitantes (IBGE, 2017a).

Por fim, a carga fatorial "Natureza demográfica" mostra, por intermédio da Figura 4, que as condições de variação relativa da população total residente entre 2001 e 2010 e a proporção do número de óbitos ocorridos na localidade ainda são elevadas no Estado. 0 município que se destacou por apresentar índice muito alto dessa carga fatorial foi Nova Mamoré. Nesse caso, há uma relação peculiar entre o pequeno município com 28.891 habitantes (IBGE, 2017b) e a baixa densidade de 2,24 hab/ $\mathrm{km}^{2}$ (IBGE, 2017b). A cidade que é vizinha de municípios, como Rio Crespo, Alto Alegre dos Parecis e Pimenteiras do Oeste, possui 8,2\% do esgotamento sanitário adequado e 9,41 óbitos por mil nascidos vivos (IBGE, 2017b). A característica forte de mudança populacional justifica-se pelo pequeno porte da cidade e pelas novas oportunidades e demandas existentes nas localidades vizinhas. De modo geral, a variação populacional e a taxa de mortalidade dos municípios de Rondônia encontram-se dentro do panorama brasileiro.

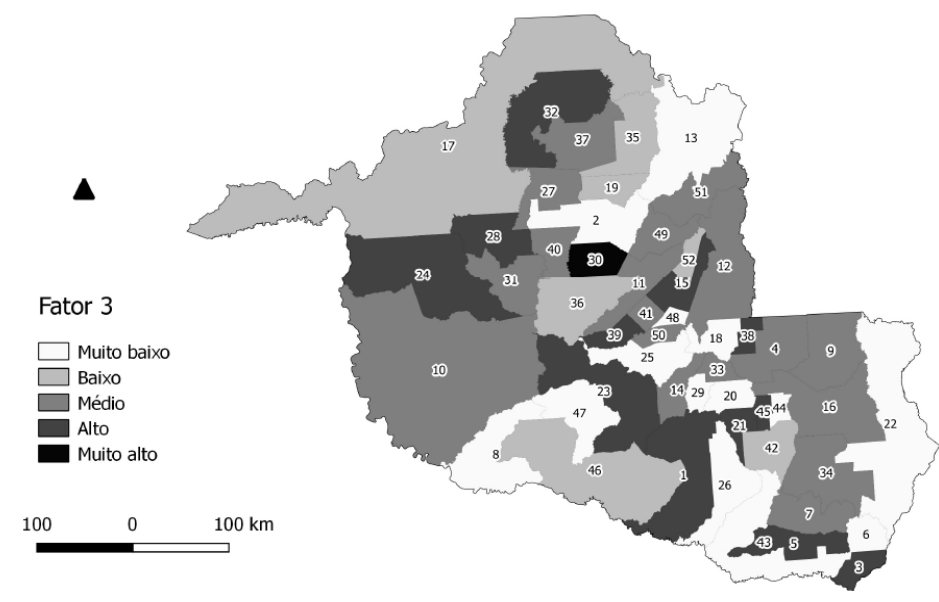

Figura 4 - Natureza demográfica. Fonte: Elaboração própria.

\section{Conclusões}

Este trabalho teve por objetivo analisar o enfoque do planejamento regional mediante a implantação de grandes projetos, no caso, a construção de usinas hidrelétricas no Estado de Rondônia. É importante ressaltar também que o objetivo do trabalho não foi investigar variáveis diretamente ligadas à implantação de GPIs, visto que outros empreendimentos e obras de grande porte foram viabilizados na região no âmbito do desenvolvimento regional.

No entanto, a análise fatorial permitiu uma observação, isto é, uma "fotografia" de como os municípios rondonianos se comportam mediante aspectos direcionados à infraestrutura, demografia e fatores econômicos e sociais. Os resultados apontaram para a caracterização de três fatores distintos, a saber: i) Dinâmica econômica; ii) Estrutura básica; e iii) Natureza demográfica. Tais fatores apresentaram características peculiares ao processo de urbanização em Rondônia.

A partir dos resultados, observou-se que as três cargas fatoriais se distinguem entre os aspectos urbanos e mais carentes de infraestrutura. A primeira carga fatorial denominada de "Dinâmica econômica" apresenta características tipicamente urbanas e indica um elevado coeficiente relacionado aos aspectos econômicos (trabalho e emprego). No segundo fator (Estrutura básica), verificaram-se duas variáveis determinantes de áreas com infraestrutura sólida e/ou não voltadas a áreas urbanas, como água encanada e eletricidade. Quanto ao último fator, suas características remetem a uma área que pode ser denominada de "Natureza demográfica", pois configura relações típicas de cidade de pequeno porte, porém com relativo déficit na proporção de natalidade e mortalidade, além de outros fatores significativos entre os municípios vizinhos e sua absorção de mão de obra. 
Com base nos resultados observados, e como sugestão de políticas públicas para o Estado de Rondônia, sugere-se a implementação de algumas medidas que viabilizem maior infraestrutura aos municípios necessitados, assim como a diminuição dos efeitos negativos dos impactos de implantação das obras em relação à qualidade de vida da população. É oportuno ressaltar que grandes projetos que envolvem, por exemplo, rodovias metropolitanas, projetos de reabilitação de áreas portuárias, megaeventos que abrangem a construção de equipamentos esportivos e projetos imobiliários, plantas industriais, grandes condomínios residenciais, grandes obras de usinas hidrelétricas e outros investimentos públicos e privados de expansão territorial merecem destaque, principalmente no que se refere à ampliação dos espaços de valorização imobiliária e à reprodução das desigualdades sociais nas grandes metrópoles brasileiras (Oliveira, 2012).

Desta forma, no caso do Estado de Rondônia, destaca as especificidades da região e mostra uma forte dependência de políticas públicas municipais que concentram um volume expressivo de investimentos em infraestrutura socioeconômica. Em virtude do processo de dependência, seria de grande importância não somente investimentos de iniciativas federais, mas também na esfera privada, criando assim um ambiente profícuo de investimentos privados, imobiliários e produtivos. Tal movimento reforçaria e poderia explicar as transformações em curso no Estado de Rondônia. Logo, destaca-se como uma das alternativas de longo prazo para as regiões a construção de alternativas econômicas populares posteriormente ao período de grandes obras de infraestrutura, bem como de políticas urbanas locais capazes de recuperar a valorização imobiliária causada pelos investimentos públicos.

Por fim, para análises futuras, pretende-se estudar uma evolução temporal das regiões (municípios) de Rondônia, utilizando uma diversificada base de informações com o objetivo de captar as influências e os impactos dos grandes projetos de investimentos ao longo do tempo.

\section{Referências}

Aproveitamento Hidrelétrico Santo Antônio - AHE Santo Antônio. (2008). Projeto básico ambiental Aproveitamento Hidrelétrico Santo Antônio (Vol. IV). São Paulo: Madeira Energia S.A.

Bernardes, L. (1986). Política urbana: uma análise da experiência brasileira. Análise e Conjuntura, 1(1), 83-119.

Bortoleto, E. M. A. (2001). Implantação de grandes hidrelétricas: desenvolvimento, discurso e impactos. Revista Geografares, 2, 53-62.

Brasil. Programa de Aceleração do Crescimento - PAC. (2008). Informações sobre o Programa de Aceleração do Crescimento. Brasília. Recuperado em 13 dezembro de 2017, de http://www.pac.gov.br/pub/up/relatorio/1b41397c94e4d35d16d5c054306d5708.pdf

Brasil. Ministério do Planejamento, Desenvolvimento e Gestão. (2011). Informações sobre a iniciativa para a integração da infraestrutura regional sul-americana. Brasília. Recuperado em 8 de dezembro de 2017, de http://www.planejamento.gov.br/secretaria.asp?cat=156\&sub=302\&sec=10

Cardoso, D. F., \& Ribeiro, L. C. S. (2015). Índice Relativo de Qualidade de Vida para os municípios de Minas Gerais. Planejamento e Políticas Públicas, 45, 347-375.

Diniz, C. C. (1993). Desenvolvimento poligonal no Brasil: nem desconcentração nem contínua polarização. Nova Economia, 31(1), 35-64.

Domingues, E. P., Magalhães, A. S., \& Faria, W. R. (2009). Infraestrutura, crescimento e desigualdade regional: projeção dos impactos dos investimentos do Programa de Aceleração do Crescimento (PAC) em Minas Gerais. Pesquisa e Planejamento Economico, 39(1), 121-158.

Eletronorte. (2018). Informações sobre a UHE Samuel. Brasília. Recuperado em 3 de fevereiro de 2018, de http://www.eletronorte.gov.br/opencms/opencms/pilares/geracao/estados/rondonia

Fávero, L. P., Belfiore, P., Silva, F. L., \& Chan, B. L. (2009). Análise de dados: modelagem multivariada para tomada de decisões. Rio de Janeiro: Elsevier. 
Gonçalves, E. (2006). Estrutura urbana e atividade tecnológica em Minas Gerais. Economia Aplicada, 10(4), 481502. http://dx.doi.org/10.1590/S1413-80502006000400001.

Haddad, P. R. (1996). A experiência brasileira de planejamento regional e suas perspectivas: a política regional na era da globalização. São Paulo: Centro de Estudos da Konrad Adenauer Stiftung.

Harvey, D. (1975). Social justice and the city. London: Edward Arnold.

Hoffman, R. (1993). Componentes principais e análise fatorial (3. ed., Série Didática, No. 80). Piracicaba: ESALQ. Instituto Brasileiro de Geografia e Estatística - IBGE. (2009). Relatório de atividades econômicas 2009. Rio de Janeiro. Recuperado em 5 de dezembro de 2011, de https://www.ibge.gov.br

Instituto Brasileiro de Geografia e Estatística - IBGE. (2010). Relatório de atividades econômicas 2010. Rio de Janeiro. Recuperado em 5 de dezembro de 2011, de https://www.ibge.gov.br

Instituto Brasileiro de Geografia e Estatística - IBGE. (2017a). Informações sobre Porto Velho. Rio de Janeiro. Recuperado em 14 de dezembro de 2017 de, https://cidades.ibge.gov.br/brasil/ro/porto-velho/panorama Instituto Brasileiro de Geografia e Estatística - IBGE. (2017b). Informações sobre Nova Mármore. Rio de Janeiro. Recuperado em 14 de dezembro de 2017 de, https://cidades.ibge.gov.br/brasil/ro/nova-mamore/panorama

Itaipu. (2016). Itaipu tem semestre histórico e estabelece novo recorde de geração. Recuperado em 12 de dezembro, de http://www.itaipu.gov.br/sala-de-imprensa/noticia/itaipu-tem-semestre-historico-e-estabelece-novo-recordede-geracao

Lefebvre, H. (1999). A revolução urbana. Belo Horizonte: UFMG.

Lungo, M. (2005). Grandes proyectos urbanos: una visión general. Revista Urbana, 10(37), 15-43.

Magalhães, F. N. C. (2008). Transformações socioespaciais na cidade-região em formação: a economia geopolítica do novo arranjo espacial metropolitano (Dissertação de mestrado). Instituto de Geociências, Universidade Federal de Minas Gerais, Belo Horizonte.

Manly, F. J. B. (1986). Multivariate statistical methods: a primer. London: Chapman \& Hall.

Mingoti, S. A. (2007). Análise de dados através de métodos de estatística multivariada: uma abordagem aplicada. Belo Horizonte: Editora UFMG.

Monte-Mór, R. L. (2004). A questão urbana e o planejamento urbano-regional no Brasil contemporâneo. Projeto: diretrizes para formulação de políticas de desenvolvimento regional e de ordenação do território brasileiro. Belo Horizonte: CEDEPLAR.

Monte-Mór, R. L. (2006). As teorias urbanas e o planejamento urbano no Brasil. In C. C. Diniz, \& R. L. Monte-Mór (Eds.), o que é urbano, no mundo contemporâneo (Texto para Discussão, No. 281). Belo Horizonte: UFMG/CEDEPLAR.

Moret, A. S., \& Guerra, S. M. G. (2009). Hidrelétricas no Rio Madeira: reflexões sobre impactos ambientais e sociais. Revista OIDLES, 3(7), 2009.

Moura, R. (2011). Grandes projetos urbanos. Boletim Campineiro de Geografia, 1(1).

Oliveira, F. L. (2012). Grandes projetos metropolitanos. Rio de Janeiro: Letra Capital.

Piquet, R. (1998). Cidade-empresa: presença na paisagem urbana brasileira. Rio de Janeiro: Zahar.

Ribeiro, L. C. S., Domingues, E. P., Perobelli, F. S., \& Hewings, G. J. D. (2018). Structuring investment and regional inequalities in the Brazilian Northeast. Regional Studies, 52(5), 727-739.

http://dx.doi.org/10.1080/00343404.2017.1327709.

Rondônia. Governo do Estado. (2009). Recuperado em 5 de dezembro de 2009, de http://www.rondonia.ro.gov.br/conteudo.asp?id=180

Santos, S. C. (2007). Hidrelétricas e suas consequências socioambientais. In R. Verdum (Eds.), Integração, usinas hidrelétricas e impactos socioambientais. Brasília: INESC. 
Soja, E. (2000). Postmetropolis: critical studies of cities and regions. Oxford: Blackwell.

Ultramari, C. (2006a). Grandes projetos urbanos no Brasil: conceitos, contextualização e discussão de três casos. Revista do Centro Interdisciplinar de Estudos sobre a Cidade, 1(1), 1-20.

Ultramari, C. (2006b). Planejamento territorial e projeto nacional: os desafios da fragmentação. Revista do Revista Brasileira de Estudos Urbanos e Regionais, 9(1), 1-15.

Vainer, C. (2007). Fragmentação e projeto nacional: desafios para o planejamento. In C. Diniz (Ed.), Políticas de Desenvolvimento Regional: desafios e perspectivas à luz das experiências da União Européia e do Brasil (pp. 103127). Brasília: Editora UnB.

Vainer, C. B., \& Araujo, F. G. B. (1992). Grandes projetos hidrelétricos e desenvolvimento regional. Rio de Janeiro: CEDI.

Verdum, R. (2007). Obras de infraestrutura no contexto da integração Sul Americana. In R. Verdum (Ed.), Integração, usinas hidrelétricas e impactos socioambientais. Brasília: INESC.

Editor: Rodrigo Firmino

Recebido: Fev. 14, 2018

Aprovado: Out. 30, 2018 
Anexo 1 - Legenda com o nome dos municípios de Rondônia

\begin{tabular}{|c|c|c|c|}
\hline ID & Município & ID & Município \\
\hline 1 & Alta Floresta D'Oeste & 27 & Alto Paraíso \\
\hline 2 & Ariquemes & 28 & Buritis \\
\hline 3 & Cabixi & 29 & Novo Horizonte do Oeste \\
\hline 4 & Cacoal & 30 & Cacaulândia \\
\hline 5 & Cerejeiras & 31 & Campo Novo de Rondônia \\
\hline 6 & Colorado do Oeste & 32 & Candeias do Jamari \\
\hline 7 & Corumbiara & 33 & Castanheiras \\
\hline 8 & Costa Marques & 34 & Chupinguaia \\
\hline 9 & Espigão D'Oeste & 35 & Cujubim \\
\hline 10 & Guajará-Mirim & 36 & Governador Jorge Teixeira \\
\hline 11 & Jaru & 37 & Itapuã do Oeste \\
\hline 12 & Ji-Paraná & 38 & Ministro Andreazza \\
\hline 13 & Machadinho D'Oeste & 39 & Mirante da Serra \\
\hline 14 & Nova Brasilândia D'Oeste & 40 & Monte Negro \\
\hline 15 & Ouro Preto do Oeste & 41 & Nova União \\
\hline 16 & Pimenta Bueno & 42 & Parecis \\
\hline 17 & Porto Velho & 43 & Pimenteiras do Oeste \\
\hline 18 & Presidente Médici & 44 & Primavera de Rondônia \\
\hline 19 & Rio Crespo & 45 & São Felipe D'Oeste \\
\hline 20 & Rolim de Moura & 46 & São Francisco do Guaporé \\
\hline 21 & Santa Luzia D'Oeste & 47 & Seringueiras \\
\hline 22 & Vilhena & 48 & Teixeirópolis \\
\hline 23 & São Miguel do Guaporé & 49 & Theobroma \\
\hline 24 & Nova Mamoré & 50 & Urupá \\
\hline 25 & Alvorada D'Oeste & 51 & Vale do Anari \\
\hline 26 & Alto Alegre dos Parecis & 52 & Vale do Paraíso \\
\hline
\end{tabular}

Fonte: Elaboração própria. 